\title{
Prevalence of Candida species from samples of women population from Maputo, Mozambique.
}

Schirmer, $\mathrm{H}^{3}$ Samo Gudo ${ }^{1}$, Langa, $\mathrm{JP}^{2}$ Cunha, $\mathrm{GR}^{3}$ Comé, $\mathrm{CE}^{2}$, Alfredo, $\mathrm{O}^{2}$, Cantarelli, VV ${ }^{4}$, Cotonia, E², Nhassengo, $\mathrm{F}^{2}, \mathrm{Nhantumbo}^{2} \mathrm{AA}^{2}, \mathrm{Cuco}^{2}$ $\mathrm{AZ}^{2}$

${ }^{1}$ National Institute of Health, Maputo, Mozambique; ${ }^{2}$ Microbiology Laboratory - INS, Maputo, Mozambique; ${ }^{3}$ Federal University of Health Sciences of Porto Alegre, Porto Alegre, Brazil,; ${ }^{4}$ Feevale University, Novo Hamburgo, Brazil

\section{OBJECTIVE}

Vulvovaginal candidiasis (VVC) represents the most frequent mucocutaneous mycoses caused by yeast of the genus Candida. It is the third cause for all cases of vulvovaginitis in reproductive-aged women and, about $8 \%$ of women suffer recurrent candida vulvovaginitis. Besides the pathogenesis of symptomatic VVC is not clear and defined, some studies have been shown the increasing prevalence of azole-resistant strain of Candida albicans and, isolation of species with reduced sensibility to fluconazole as C.glabrata and C.krusei. To establish some politics to prevention and control of diseases, is necessary to identify which pathogens are circulating in that specific population. So, the presented study was performed to assess for the first time the prevalence of Candida species isolated from vaginal secretion from symptomatic women from Maputo - Mozambique.

\section{METHODS}

The samples were collected of women with symptoms of vulvovaginitis, attend in the Reference Center for Sexually Transmitted Infections of the Health Center May 1st to the National Institute of Health, in Maputo - Mozambique. The patients are referred from the various health services as: Service of Assistance and Support to Young People (SAAJ), Prenatal Consultation, Chronic Disease Consultation (CDC), Children's Consultation at Risk (CCR), Family Planning and Screening. However, most of the patients are from the SAAJ. It is a part of National Surveillance of Sexual Transmission Infection, from Mozambique. The samples were obtained during May 2016 to September 2017 and when suspicious to VVC were incubated in Sabouraud agar plates to $37^{\circ} \mathrm{C}$. The Candidalike growths the DNA was extracted to confirm the species by multiplex real-time PCR. To this technique was used a specific anti-sense primer based on variability in the internal transcribed spacer (ITS) region of ribosomal DNA to differentiate species. The reaction consisted a PCR mix containing SYBR green as fluorescent and running on LightCycler instrument (Roche) where Candida identification could be obtained by analyzing the different melting points of the different species.

\section{RESULTS}

In this period a total of 91 samples showed a Candida-like grothws. When Multiplex PCR was done, 68 (74,73\%) were identified as C.albicans, 7 (7,69\%) C.glabrata and 1 $(1,09 \%)$ C.krusei (Table 1). Seventeen samples showed negative results after PCR analyzes. One hypothesis is that isolates are of other genera of yeast and need to be confirmed using other primers. The average age of women was 22 , ranging 15 to 39 years.

\begin{tabular}{l|c|}
\hline $\begin{array}{l}\text { Age (median) } \\
\text { Species }\end{array}$ & $\begin{array}{c}22(15 \text { to } 39 y) \\
\text { Frequency }\end{array}$ \\
\hline $\begin{array}{l}\text { C.albicans } \\
\text { C.glabrata }\end{array}$ & $74,72 \%$ \\
\hline C.krusei & $7,69 \%$ \\
\hline $\begin{array}{l}\text { Negative to } \\
\text { Candida } \text { PCR }\end{array}$ & $1,09 \%$ \\
identification & $16,50 \%$ \\
\hline
\end{tabular}

Table 1. Frequency of Candida species isolated from vaginal secretion

\section{CONCLUSION}

The present work has provided recent data on the prevalence Candida species in a specific population of Maputo, and it are the first dates about this specific population. Such data is critical for establishment of therapeutic strategies and measures for prevention and control. Besides C.albicans was the most prevalent, we detected two other species that show reduced sensibility to fluconazole and usually reported in recurrence cases, which show the importance of good tools to diagnose and correct species identification.

REFERENCES

1. Gunther LS et al. Prevalence of Candida albicans and non-albicans isolates from vaginal secretions: comparative evaluation of colonization, vaginal candidiasis and recurrent vaginal candidiasis in diabetic and non-diabetic women. São Paulo Med J (2014).

2. Sadeghi G et. Al. Emergence of non-Candida albicans species: Epidemiology, phylogeny and fluconazole susceptibility profile. J Mycol Med 2018, 28(1):51-58. 3. Blostein F et al. Recurrent vulvovaginal candidiasis Ann Epidemiol 2017, 27(9): 575-582. 